\title{
STANDARDS ASSOCIATION OF NEW ZEALAND
}

\author{
Comments on Chapter 8 of N.Z.S.S. 1900
}

\section{R. J. P. Garden*}

Prompted by the Editorial in Vol. 4 No. 1 of the Bulletin, I comment on some items of Table 5B of Amendment No. 3 to Chapter 8 of N.Z.S.S.1900.

A. Why not include also requirements for forces in the lateral horizontal direction?

B. As is the case for some other items in Tables 5A, and 5B, the minimum value of $\mathrm{C}$ is to be as given by Clause 8.36. $1^{\text {" }}$. Perhaps it is not important that 8.36 .1 relates to "Total horizontal forces" and stipulates compliance with Table 5A (not table 5B) but it does require that the value of $C$ be determined from figures 2 (zoning) and also from the period of the building "in the direction under consideration"using the curves in Figure 1. I would like to hear of it, if there is any direction, Iongitudinal, lateral or vertical, for which the period of the building as a whole can be sensibly used to derive a value. of $C$ whichis suitable for the vertical seismic forces on horizontally-cantilevered members.

C. Against vertically downward forces this item 5 requires that we design for $6 \mathrm{C}$ (dead load plus seismic live load), where the minimum value of $C$ may be between 0.04 and 0.16 in accordance with derivation from Figures 1 \& 2 .

As vertical seismic accelerations are normally $1 / 4$ to $1 / 3$ of the horizontal accelerations, the above requirement does not appear consistent with item 2 where the minimum requi rements for horizontal seismic forces on cantilevered parapets etc. are stated as $6 \times 0.08$ (dead load) for all zones. I concede there is a possibility that justification may be advanced for this, but the subsequent matter heightens suspicion.

D. Against vertically upward forces we are required to design for $3.0 \mathrm{x} C$ (dead load plus seismic live load), where the minimum value of $C$ is again within the range 0.04 to 0.16. In this case, however, we are forbidden to take the gravity effects of dead and Iive load as reducing this force. For such an upward seismic force to be imposed on the member, the member must develop a downward acceleration relative to the body of the building, of $(1+C) g$ and the live load must be tied down to the member and be dragged down with it. Why should vertically upward seismic forces be taken at about twice the magnitude of vertically downward seismic forces? After al1, eventual collapse downward is a more real threat than failure by levitation.

I would add that we are scarcely justified

- Partner, E. R. Garden and Partners, Dunedin. in tossing in a singular and severe requirement for vertical seismic forceswithout some consistent consideration of related matters. We might, for instance, make similar stipulations to prevent collapse under uplift, of those slender-ribbed prestressed units which have no bottom flanges.

E. I do not understand why item 9 of Table 5B should allow a steam boiler, which is part of a building and may therefore oscillate unfavourably with respect to the main structure, and which may have cross braced supports, and which has dangerous contents, to have a smaller value of $K$ than given in $3(\mathrm{~b})$ of Table $5 \mathrm{~A}$ for water tanks etc.

There are many clauses in the chapter and in Amendment No. 3 which leave me dissatisfied, but one should perhaps ignore the more minor imperfections. In 8.2., there is no need to define a Diaphragm as a horizontal member, and they certainly do not al ways have flanges. It is undesirable to use definitions which are at variance with long established usage. I suggest:- Diaphragm means a member having a web or membrane and which serves to distribute or transfer forces between other members through stresses in the plane of the web. The web may be a continuous plate or of open trussed construction. (Parking ramps, hopper slabs etc. are non-horizontal diaphragms; and vertical diaphragms are common-place in bridges: walls of buildings supply diaphragm action as commonly as do walls).

Ductility Factor as applied to an individual member has a reasonably precise meaning. As applied to a whole building, it does not have so precise or constant a meaning, even for the one building. Referring to the revised 12.9 .1 . of M.P.12, how does one assess by this method, the required element ductility in an upper storey? over all "building ductility" is not greatly dependent upon member ductility of upper storey members.

In 8.18.2. "lateral force transverse to the rails" is a tautology and "lateral force acting along the rails" is fundamental1y absurd. The wording of SEAOC should not be taken as model English and the words "horizontal" and "longitudinal" are available. 